\title{
Perceived behavioural predictors of late initiation to HIV/AIDS care in Gurage zone public health facilities: a cohort study using health belief model
}

\author{
Teklemichael Gebru ${ }^{1 *}$, Kifle Lentiro ${ }^{1}$ and Abdulewhab Jemal ${ }^{2}$
}

\begin{abstract}
Objective: The study was aimed to measure incidence density rate and identify perceived behavioural believes of late initiation to HIV/AIDS care in Gurage zone public health facilities from September 2015 to November 2016.

Results: The incidence density rates of late initiation to HIV/AIDS care were 2.21 per 100 person-months of observation. HIV positive individuals who did not perceived susceptibility were 8.46 times more likely delay to start HIV/AIDS care than their counter parts $[\mathrm{OR}=8.46(95 \% \mathrm{Cl} 3.92,18.26)]$. HIV infected individuals who did not perceived severity of delayed ART initiation were 6.13 time more likely to delay than HIV infected individuals who perceived its severity $[O R=6.13(95 \% \mathrm{Cl} 2.95,12.73)]$. HIV positive individuals who didn't have self-efficacy were 2.35 times more likely delay to start HIV/AIDS care than HIV positive individuals who have self-efficacy [OR $=2.35(95 \% \mathrm{Cl} 1.09,5.05)]$.

Conclusions: The study revealed that high incidence density rates of delayed initiation for HIV care and variations were explained by poor wealth, and perceived threat and benefit. Therefore, interventions should be designed to initiate care at their diagnosis time.
\end{abstract}

Keywords: Perceived behaviour, Late initiation, HIV/AIDS care

\section{Introduction Background}

Human immunodeficiency virus (HIV) is a global challenge that affects about 35.3 million people lives with HIV and 1.6 million people kills in 2012 [1,2]. Sub-Saharan Africa remnants the most seriously affected region by the disease, nearly one in every 20 (4.9\%) individuals were infected, this shares $69 \%$ of the world population who have HIV infection [3]. Since the index case was detected in Ethiopia in 1984, about 1.3 million individuals living with the virus, and HIV/AIDS killed millions people and lefts 744,100 orphan children [2]. The health status of HIV positive individuals at the time of Antiretroviral

\footnotetext{
*Correspondence: teklemichaelgebru@gmail.com

${ }^{1}$ Department of Public Health, College of Medicine and Health Science, Wolkite University, Wolkite, Ethiopia

Full list of author information is available at the end of the article
}

Therapy (ART) initiation contributes vital role for their health conditions [3-6].

World Health Organization (WHO) recommends to all HIV infected individuals whose CD4 counts of $\leq 500$ cells $/ \mu \mathrm{L}$ should start ART regardless of the presence or absence of clinical symptoms and/or individuals with advanced clinical disease (clinical stage 3 or 4 ) should start ART irrespective of their CD4 cell count threshold, which is currently accepted and applied in Ethiopian [7]. ART starting at CD4 levels higher than 200 or 250 cells/ $\mu \mathrm{L}$ increases the survival time by $20 \%$. Furthermore, initiation of ART has also initiated hope to people living with HIV/AIDS that credit to improve the quality of life [8, 9]. However, delayed ART initiation causes less likely to respond the treatment, more likely to burden on healthcare financing, and have a higher mortality rate [4-6].

Health belief model (HBM) was one of the theories designed to explore preventive healthy behaviour if a 
person has positive expectation. Thus, perception of an individual can be affected by socio-demographic factors, level of knowledge, threat, available interventions and/or their barriers, and influence of others [10].

\section{Statement of the problem}

Significant quantity (15-43\%) of HIV positive individuals living in third world countries were came for care very delay with severe disease [8]. Delayed initiation of ART is associated with higher rates of HIV-related morbidity and mortality [4]. In sub-Saharan Africa, the overall coverage of ART initiation was $48 \%$ of those in eligible, emerging evidence showed that up to $59 \%$ of people living with HIV were either lost to follow-up or started ART at late stage of the disease $[3,4]$.

In Ethiopia, the coverage of ART was 53\% (336,160 persons) of those eligible for the treatment (CD4 cell counts $<500$ cells $/ \mu \mathrm{L})[8,11]$. In effect, the country planned to increase ART coverage to reach $95 \%$. Perhaps, studies conducted in different area of the country shows the prevalence of delayed presentation to HIV/AIDS care were $40,38.8$ and $33.1 \%$, [12-15].

Delayed presenting hinders people from obtaining maximum benefit of being screened for tuberculosis and sexually transmitted infections (STI), timely ART initiation, and counselling to prevent further opportunistic infections [6, 16-20]. Considering its low prevalence of $\mathrm{HIV/care,} \mathrm{improvement} \mathrm{of} \mathrm{ART} \mathrm{treatment} \mathrm{is} \mathrm{a} \mathrm{priority}$ intervention area of the Ethiopian ministry of health.

In this regard, there is no published research report on behavioural aspect of ART initiation. Thus, the purpose of the study was to measure incidence density rate and explore perceived behavioural believes that may predispose to late initiation to HIV care that helps to design effective intervention in Ethiopia and beyond.

\section{Main text}

\section{Method and subjects}

\section{Study area and period}

The study was performed at Gurage zone that has 1,583,824 populations; of these 744,397 were males and 839,427 females. The population of area get healthcare service from five hospitals and 70 health centres by 1526 health professionals. Moreover, 21 health facilities were providing pre-ART and ART services for 4143 and 2597 people, respectively [21-23]. We follow them and interview at their time of initiation about the predictors of initiation as a case-control approach from September 2015 to November 2016.

\section{Study design}

Cohort study that has both prospective and retrospective components using health belief model was employed. All peoples living with HIV in Gurage zone were source population; whereas people living with HIV linked pre-ART clinics in the study area during the study period were study population.

\section{Eligibility criteria}

At the time of study in Ethiopia ART enrolment is expected to be started at CD4 count less than 500 cell $/ \mu \mathrm{L}$ or WHO clinical stage III or IV. However, HIV infected peoples diagnosed with CD4 count greater than 500 cell/ $\mu \mathrm{L}$ were linked to pre-ART clinic for follow-up not yet started ART. Therefore, among the HIV positive individuals linked to pre-ART individuals initiated ART with WHO clinical stage of III or IV or a CD4 count less than 350 cell $/ \mu \mathrm{L}$ were included as CASE and for their counterpart individuals who initiates the treatment with WHO clinical stage of I or II or CD4 count more than or equal to $350 \mathrm{cell} / \mu \mathrm{L}$ were included as CONTROL [24-26]. However, HIV positive peoples who are directly initiated the treatment and children less than 18 years' age were excluded from the study.

\section{Sample size determination and sampling technique}

The sample size was calculated using STATCALC program of EPI INFO version 7 statistical packages by assuming; the proportion of adult illiteracy among cases 64\% (gave maximum sample size) [11], 95\% CI 80\% power, case to control ratio of 1:1 to detect an odds ratio of 2.0 , and $10 \%$ non-response rate. Accordingly, the calculated optimal sample size was 320 (160 cases and 160 controls) and consecutive sampling were used.

\section{Data collection and quality assurance}

Data was collected by trained diploma and above holder health professionals using Amharic version adapted interviewer administered, pre-coded and pre-tested structured instrument. The tool includes socio-demographic characteristics, wealth index computed from 16 items that ranges $0-16$, knowledge (12 items of yes or no response that ranges from 0 to 12) and behavioural perceptions including threat (both susceptibility and severity) (11 Likert scale items that ranges from 11 to 55 ), benefit (5 items that ranges from 5 to 25), barrier (5 items that ranges from 5 to 25), Self-efficacy (4 items that ranges from 4 to 20 ) and cue-to-action (9 items of yes or no response that ranges from 0 to 9) (Additional file 1) [27-30]). Furthermore, base line data was collected from their medical record such as time of diagnosis, level of $\mathrm{CD} 4$ count and WHO clinical stage.

Data collection instrument was pre-tested on 5\% of the actual sample size and 3 days training with mock was given to data collector and supervisors prior the process 
of data collection. Furthermore, double data entry was made using Epi-data software for validation.

\section{Data processing and analysis}

Statistical packages such as Epi-data 3.1 for data entry, STATA- 12 to calculate incidence density rate and SPSS20 to compute numerical values and identify significant predictors. Level of knowledge was computed after reversely recoding the response it ranges from 0 to 12 and categorised as "informed" and "uninformed" for the value above the mean and below the mean, respectively. For HBM constructs initially, oppositely phrased items were reversely coded and factor analysis were applied to assess; factor-item correlation matrix at least two variables greater than 0.30, Barlett test of sphericity below 0.001 and Kaiser-Meyer-Olkin (KMO) 0.6 or above with Oblique rotation [10]. Furthermore, parallel analysis was used to estimate eigen value [32] and reliability analysis to compute Cronbach alpha coefficient with 0.70 and above was accepted as internally consistent items. Furthermore, care was taken to deal with missing values by excluding cases pairwise. Lastly all the constructs of HBM were dichotomised as "Yes" and "No" response for the value above the mean and below the mean based on each rage, respectively.

Predictor assessment was made by constructing selective model and only variables with $\mathrm{p}<0.25$ in the binary regression were further considered to final model [33]. Then, backward stepwise logistic regression method was applied to control the effect of confounding factors [34]. Odds ratio (OR) with 95\% confidence interval (CI) were used to estimate the strength of association and its stability. For all statistically significant tests, the cut-off value set is $\mathrm{p}$ value less than 0.05 .

\section{Results}

\section{Socio-demographic characteristics}

We planned to participated 320 individuals in the study; however, 317 subjects deployed for the study that makes $99.06 \%$ response rate. The mean age of the study participants was 33 with 8 standard deviations. Majority of the study participants were females 189 (59.6\%) and single by their marital status 131 (41.3\%). Most of the respondents' highest educational level was none or didn't get formal education 127 (40.1\%) followed by College graduates and above 91 (28.7\%). Furthermore, half of the study participants stay with HIV/AIDS at least for 5 years 165 (52.1\%) (Table 1).

\section{Incidence density rate of HIV/AIDS care}

The person time incidence rate from pre-ART to ART initiation of HIV positive individuals were 4.46 per 100 person-months of observation. Furthermore, the
Table 1 Socio-demographic characteristics of study participants for late presentation to HIV/AIDS care in Gurage zone public health facilities, $n=317$, Sep. 2015 to Nov. 2016

\begin{tabular}{|c|c|c|}
\hline \multirow[t]{3}{*}{ Variable description } & \multicolumn{2}{|c|}{ ART initiation condition } \\
\hline & Case & Control \\
\hline & Count (\%) & Count $(\%)$ \\
\hline \multicolumn{3}{|l|}{ Gender } \\
\hline Male & $84(52.5)$ & $44(28.0)$ \\
\hline Female & $76(47.5)$ & $113(72.0)$ \\
\hline \multicolumn{3}{|l|}{ Marital status } \\
\hline Single & $64(40.0)$ & $67(42.7)$ \\
\hline Married & $33(20.6)$ & $23(14.6)$ \\
\hline Divorce & $32(20.0)$ & $44(28.0)$ \\
\hline Widowed & $31(19.4)$ & $23(14.6)$ \\
\hline \multicolumn{3}{|l|}{ Highest education } \\
\hline None or can't get formal education & 49 (30.6) & $78(49.7)$ \\
\hline Elementary & $35(21.9)$ & $8(5.1)$ \\
\hline Secondary & $36(22.5)$ & $20(12.7)$ \\
\hline College graduate and above & $40(25.0)$ & $51(32.5)$ \\
\hline \multicolumn{3}{|l|}{ Occupational status } \\
\hline Unemployed & $23(14.4)$ & $12(7.6)$ \\
\hline Student & $7(4.4)$ & $8(5.1)$ \\
\hline House wife & 49 (30.6) & $74(47.1)$ \\
\hline Employed & $81(50.6)$ & $63(40.1)$ \\
\hline \multicolumn{3}{|l|}{ Wealth index } \\
\hline Poor & $67(41.9)$ & $35(22.3)$ \\
\hline Medium & $40(25.0)$ & $63(40.1)$ \\
\hline Rich & $53(33.1)$ & $59(37.6)$ \\
\hline \multicolumn{3}{|l|}{ Time living with HIV } \\
\hline Less than 1 year & $46(28.8)$ & $31(19.7)$ \\
\hline $1-5$ years & $51(31.9)$ & $24(15.3)$ \\
\hline Greater than 5 years & $63(39.4)$ & $102(65.0)$ \\
\hline
\end{tabular}

incidence density rates of delay to HIV/AIDS care were 2.21 per 100 HIV positive person-months of observation.

\section{Behavioural factors related to late HIV/AIDS care}

More than half of both case and control study participants had have a knowledge on ART 105 (65.6\%) and 121 (77.1\%), respectively. Twenty-four $(15.0 \%)$ of the cases and $91(58.0 \%)$ of the control were perceived severe consequences of delay to start HIV/AIDS care. Around onefourth of the cases $29(18.1 \%)$ and more than half of the controls 93 (59.2\%) were perceived to get benefit from early initiation of HIV/AIDS care (Table 2).

\section{Independent predictors of late initiation to HIV/AIDS care}

Uniformed HIV positive individuals about HIV care were 1.94 times more likely to delay HIV/AIDS care than 
Table 2 Behavioural factors related to late initiation for HIV/AIDS care in Gurage zone public health facilities, $\mathrm{n}=317$, Sep. 2015 to Nov. 2016

\begin{tabular}{|c|c|c|}
\hline \multirow[t]{3}{*}{ Variable } & \multicolumn{2}{|c|}{ ART initiation condition } \\
\hline & Case & Control \\
\hline & Count (\%) & Count (\%) \\
\hline \multicolumn{3}{|l|}{ Knowledge } \\
\hline Informed & $105(65.6)$ & $121(77.1)$ \\
\hline Uninformed & $55(34.4)$ & $36(22.9)$ \\
\hline \multicolumn{3}{|c|}{ Perceived susceptibility } \\
\hline Yes & $33(20.6)$ & $129(82.2)$ \\
\hline No & $127(79.4)$ & $28(17.8)$ \\
\hline \multicolumn{3}{|c|}{ Perceived severity } \\
\hline Yes & $43(26.9)$ & $133(84.7)$ \\
\hline No & $117(73.1)$ & $24(15.3)$ \\
\hline \multicolumn{3}{|c|}{ Perceived benefit } \\
\hline Yes & $29(18.1)$ & $93(59.2)$ \\
\hline No & $131(81.9)$ & $64(40.8)$ \\
\hline \multicolumn{3}{|c|}{ Perceived barrier } \\
\hline Yes & $58(36.2)$ & $59(37.6)$ \\
\hline No & $102(63.8)$ & $98(62.4)$ \\
\hline \multicolumn{3}{|l|}{ Self-efficacy } \\
\hline Yes & $57(35.6)$ & $93(59.2)$ \\
\hline No & $103(64.4)$ & $64(40.8)$ \\
\hline \multicolumn{3}{|l|}{ Cue to action } \\
\hline Yes & $87(54.4)$ & $59(37.6)$ \\
\hline No & $73(45.6)$ & $98(62.4)$ \\
\hline
\end{tabular}

informed individuals $[\mathrm{OR}=1.94$ (CI 1.06, 3.56)]. HIV positive individuals who did not perceived susceptibility were 8.46 time more likely delay to start HIV care than their counter parts $[\mathrm{OR}=8.46(95 \%$ CI 3.92, 18.26)]. HIV infected individuals who did not perceived severity of delayed ART initiation were 6.13 time more likely to delay than HIV infected individuals who perceived its severity $[\mathrm{OR}=6.13(95 \%$ CI $2.95,12.73)$ ]. HIV positive individuals who didn't have self-efficacy were 2.35 time more likely delay to start HIV care than HIV positive individuals who have self-efficacy $[\mathrm{OR}=2.35(95 \% \mathrm{CI}$ 1.09, 5.05)] (Table 3).

\section{Discussion}

In this study it was revealed that the incidence density for late HIV care were high, this could be explained by after diagnosis peoples may searful to start the care within short period of time. Knowledge about the care was associated to delay the treatment. HIV positive individuals who perceived susceptibility were significantly associated with late presentation to HIV care which is consistent with the studies done in Wollo $[35,36]$. The higher likelihood of individuals did not perceived susceptibility for presenting late to HIV/AIDS care could be explained by fearful to start care after diagnosis. HIV positive individuals who did not perceived the seriousness were significantly associated with late presentation to HIV/AIDS care which is consistent with the studies done in Tigray [OR=4.3, (95\% CI 2.26-8)] [37], and Durban [36]. The higher likelihood of individual not perceived seriousness

Table 3 Independent predictors of late initiation to HIV/AIDS care in Gurage zone public health facilities, $\mathbf{n}=317$, Sep. 2015 to Nov. 2016

\begin{tabular}{|c|c|c|c|c|}
\hline \multirow[t]{3}{*}{ Predictor variables } & \multicolumn{2}{|c|}{ ART initiation condition } & \multicolumn{2}{|l|}{ OR $(95 \% \mathrm{Cl})$} \\
\hline & Case & Control & Crude & Adjusted \\
\hline & Count (\%) & Count (\%) & & \\
\hline \multicolumn{5}{|l|}{ Knowledge } \\
\hline Informed & $105(65.6)$ & $121(77.1)$ & 1 & 1 \\
\hline Uninformed & $55(34.4)$ & $36(22.9)$ & $3.74(2.35,5.96)$ & $1.94(1.06,3.56)$ \\
\hline \multicolumn{5}{|c|}{ Perceived susceptibility } \\
\hline Yes & $26(16.2)$ & $106(67.5)$ & 1 & 1 \\
\hline No & $134(83.8)$ & $51(32.5)$ & $17.73(10.13,31.04)$ & $8.46(3.92,18.26)$ \\
\hline \multicolumn{5}{|l|}{ Perceived severity } \\
\hline Yes & $24(15.0)$ & $91(58.0)$ & 1 & 1 \\
\hline No & $136(85.0)$ & $66(42.0)$ & $15.08(8.63,26.34)$ & $6.13(2.95,12.73)$ \\
\hline \multicolumn{5}{|l|}{ Perceived benefit } \\
\hline Yes & $29(18.1)$ & $93(59.2)$ & 1 & 1 \\
\hline No & $131(81.9)$ & $64(40.8)$ & $6.56(3.93,10.96)$ & $3.12(1.53,6.33)$ \\
\hline \multicolumn{5}{|l|}{ Self-efficacy } \\
\hline Yes & $57(35.6)$ & $93(59.2)$ & 1 & 1 \\
\hline No & $103(64.4)$ & $64(40.8)$ & $2.63(1.67,4.13)$ & $2.35(1.09,5.05)$ \\
\hline
\end{tabular}


presenting late to HIV care could be explained by lack of information particularly on early initiation (Additional file 1).

HIV positive individuals who did not perceived benefit from HIV care and individuals who had lost self-efficacy were significantly associated with late presentation to HIV care which is consistent with the studies done in Vietnam, and Wollo [30, 35-38]. The higher likelihood of individuals not perceived benefit from the care presents lately could be explained due to social stigma, lack of knowledge, or doesn't perceiving medical care have advantageous in case of once HIV positive.

\section{Conclusions}

The study revealed that high incidence density rates of delayed HIV care initiation and variation explained by level of uninformed about the care, perceived threat, and self-efficacy. Therefore, programs should be designed for effective counselling focused on the consequence of late ART initiation, adherence and to start HIV care immediately at their time of diagnosis.

\section{Limitation of the study}

This study lacks triangulation with qualitative findings to address unexpected issues and culture based variation. Furthermore, this research may be subjected to recall bias and social desirability.

\section{Additional file}

Additional file 1. Questionnaire.

\section{Abbreviations}

AIDS: acquired immune deficiency syndrome; ART: Antiretroviral Therapy; Cl: confidence interval; HIV: human immunodeficiency virus; KMO: Kaiser-MeyerOlkin; OR: odds ratio; SPSS: Statistical Package for Social Science; STI: sexually transmitted infection; WHO: World Health Organization; $\mu \mathrm{L}$ : micro liter.

\section{Authors' contribution}

TG framed the study and analyzed the data. $\mathrm{KL}$ and $\mathrm{AJ}$ contributed to the design and data collection of the study. The manuscript was prepared by all authors. All authors read and approved the final manuscript.

\section{Author details}

${ }^{1}$ Department of Public Health, College of Medicine and Health Science, Wolkite University, Wolkite, Ethiopia. ${ }^{2}$ Department of Medicine, College of Medicine and Health Science, Wolkite University, Wolkite, Ethiopia.

\section{Acknowledgements}

First and foremost, we would like to express our deepest gratitude to data collectors, supervisors and the study participants for their cooperation. Finally, we extend our appreciation to Guragea zone health department for its cooperation

\section{Competing interests}

The authors declare that they have no competing interests.

\section{Availability of data and materials}

The datasets used and/or analysed during the current study are available from the corresponding author on reasonable request.

\section{Consent for publication}

Not applicable.

\section{Ethics approval and consent to participate}

The study was approved ethically by institutional review board of Wolkite University. Furthermore, study participants were introduced about the study, respondent's right, autonomy and willingness to participate in the study were respected and written consent from each study participants were obtained prior to each interview. Names and other personal information of respondents were not recorded. Any information was/will be kept confidential and only used for this research. During data collection privacy of respondents were kept and it is free to withdrawal from the interviewed at any time.

Source of fund

This study was financially supported only for data collection by Wolkite University, Ethiopia.

\section{Publisher's Note}

Springer Nature remains neutral with regard to jurisdictional claims in published maps and institutional affiliations.

Received: 30 October 2017 Accepted: 7 May 2018

Published online: 22 May 2018

References

1. USAID. UNAIDS report on the global AIDS epidemic 2013. WHO Library Catalogue. 2013.

2. Ethiopian Federal MoH. Strategic framework for referral and linkages between HCT and chronic HIV care services in Ethiopia. In: Center NAR, editor. Addis Ababa. 2009:1-4.

3. Sterling TR. HIV-1 RNA, CD4 T-lymphocytes, and clinical response to highly active antiretroviral therapy. AIDS. 2001;15:251-7.

4. Castilla J, et al. Late diagnosis of HIV infection in the era of highly active antiretroviral therapy: consequences for AIDS incidence. AIDS. 2002;16:1945-51

5. Egger $M$, et al. Prognosis of HIV-1-infected patients starting highly active antiretroviral therapy: a collaborative analysis of prospective studies. Lancet. 2002:360:119-29.

6. Sterling TRCR, et al. Improved outcomes with earlier initiation of highly active antiretroviral therapy among human immunodeficiency virus infected patients who achieve durable virologic suppression: longer follow-up of an observational cohort study. J Infect Dis. 2003;188:1659-65.

7. WHO. Antiretroviral therapy for HIV infection in adults and adolescents: recommendations for a public health approach 2010 revision. Geneva. 2010

8. Kigoz LM, et al. Late-disease stage at presentation to an hiv clinic in the era of free antiretroviral therapy in sub-Saharan Africa. AIDS. 2009:52(2):280-9.

9. Lubega $\mathrm{M}$, et al. Lack of pre-antiretroviral care and competition from traditional healers, crucial risk factors for very late initiation of antiretroviral therapy for HIV - a case-control study from eastern Uganda. Pan Afr Med J. 2011;8(40):2-5.

10. Champion VL, Skinner CG, et al. The health belief model. In: Karen G, editor. Health behavior and health education theory, research, and practice. 4th ed. San Francisco: Jossey-Bass; 2008. p. 45-65.

11. FMoH. Health sector development programme IV 2010/11-2014/15. 2010

12. Carter S. AIDs don't kill its customer: understanding barriers to access and adherence to HIV treatment among young people living in Periurban Uganda. University of British Columbia. 2009.

13. Wolbers $M$, et al. Delayed diagnosis of HIV infection and late initiation of antiretroviral therapy in the swiss HIV cohort study. HIV Med. 2008:9:397-405. 
14. Abdo Z, et al. Retrospective analysis, study of presentation to HIV care and associated factors in Shashamanne Hospital, South-eastern Ethiopia. Addis Ababa university repository. 2014.

15. Gesesew $\mathrm{H}$, et al. Factors affecting late presentation for HIV/AIDS care in Southwest Ethiopia: a case control study. Public Health Res. 2013;3(4):98-107.

16. Thanawuth $\mathrm{N}$, et al. Late HIV diagnosis and delay in CD4 count measurement among HIV-infected patients in Southern Thailand. AIDS Care. 2008:20(1):43-50.

17. WHO. Global update on HIV treatment, WHO report in partnership with UNICEF and UNAIDS. Geneva. 2013.

18. Gerardo AU. Factors associated with delayed entry into HIV medical care after HIV diagnosis in a resource-limited setting: data from a cohort study in India. PeerJ. 2013;1-e90.

19. Kamalika M, et al. Late presenters to HIV care and treatment, identification of associated risk factors in HIV-1 infected indian population. BMC Public Health. 2010;10:416.

20. Enrico G, et al. Delayed presentation and late testing for HIV: demographic and behavioral risk factors in a multicenter study in Italy. JAID Acquir Immune Defic Syndr. 2004:36(4):951-9.

21. Isaac MK, et al. Late disease stage at presentation to an HIV clinic in the era of free antiretroviral therapy in sub-Saharan Africa. JAID Acquir Immune Defic Syndr. 2010;52(2):1-12.

22. Makasi TML. Factors associated with delayed entry into HIV medical care among HIV positive people who are aware of their status in Bulawayo Zimbabwe. 2012;1(4):55-62.

23. Fiona $\mathrm{R}$, et al. Combining qualitative and quantitative evidence to determine factors leading to late presentation for antiretroviral therapy in Malawi. PLoS ONE. 2011;6(11):e27917.

24. Lubagam $M$, et al. Lack of pre-ARVs care and competition from traditional healers, crucial risk factors for very late initiation of ART for HIV: a casecontrol study from Eastern Uganda. Pan Afr Med J. 2011;8688(8):1-10.

25. Amare $Y$, et al. Factors associated with late presentation to HIV/AIDS care in South Wollo Zone, Ethiopia: a case-control study. AIDS Res Ther. 2011:8(1):8

26. Mulissa Z, et al. Patients present earlier and survival has improved, but Pre-ART attrition is high in a six-year HIV cohort data from Ethiopia. PLOS ONE. 2010:5(10):e13268.
27. Maeva A, et al. Determinants of late disease-stage presentation at diagnosis of HIV infection in venezuela: a case-case comparison. AIDS Res Ther. 2008;5(6):1-12.

28. Matthew $P$, et al. Barriers to initiation of antiretroviral treatment in rural and urban areas of Zambia : a cross-sectional study of cost, stigma, and perceptions about ART. J Int AIDS Behav. 2010;13(1):1-11.

29. Abigail $\mathrm{M}$, et al. Predictors of linkage to care following community based HIV counseling and testing in rural Kenya. AIDS Behav. 2013;16(5):1295-307.

30. Drain $P$, et al. Risk factors for late-stage HIV disease presentation at initial HIV diagnosis in Durban, South Africa. PLoS ONE. 2013;8(1):e55305.

31. Sydney R, Fox MP. Retention in HIV care between testing and treatment in Sub-Saharan Africa: a systematic review. PLoS Med. 2011;8(7):e1001056

32. O'Connor BP. SPSS and SAS programs for determining the number of components using parallel analysis and Velicer's MAP test. Behav Res Methods Instrum Comput. 2000;32:396-402.

33. Yalemzewod A, et al. Determinants of late presentation to HIV/AIDS care in Southern Tigray Zone, Northern Ethiopia: an institution based casecontrol study. AIDS Res Ther. 2015;12:40.

34. Viallefont $V$, et al. Variable selection and bayesian model averaging in case control studies. Technical report no. 343. University of Washington. 1998.

35. Abaynew, et al. Factors associated with late presentation to HIV/AIDS care in South Wollo Zone Ethiopia: a case control study. AIDS Res Ther 2011;8:8.

36. Kleinbaum K. Variable selection. In: Vittinghoff E, et al., editors. Regression methods in biostatistics: linear, logistic, survival and repeated measures models. Statistics for biology and health. New York: Springer; 2004. p. $133-47$.

37. MacCarthy S, et al. Late presentation to HIV/AIDS testing, treatment, or continued care: clarifying the use of CD4 evaluation in the consensus definition. HIV Med. 2014;15(3):130-4.

38. Sandra MC, et al. Barriers and facilitators to HIV testing and linkage to primary care: narratives of people with advanced HIV in the Southeast. NIH Public Access. 2012;21(10):1313-20. 